\title{
Systems analysis for deployment of internet of things (IoT) in the maritime industry
}

\author{
Kazuo Hiekata $^{1} \cdot$ Shinnosuke Wanaka ${ }^{2}\left(\right.$ Taiga Mitsuyuki $^{3} \cdot$ Ryuji Ueno $^{4} \cdot$ Ryota Wada $^{1} \cdot$ Bryan Moser $^{1,5}$
}

Received: 11 November 2019 / Accepted: 6 July 2020 / Published online: 16 July 2020

(c) The Author(s) 2020

\begin{abstract}
Various industries are undergoing transformation given recently available pervasive sensors, low-cost and low-latency digital communication, and distributed control technologies. The objective of this paper is to support the introduction of Internet of things (IoT) technologies in the maritime industry. The maritime industry is analyzed as a system of systems to define performance criteria and functions to be modeled and analyzed through simulation. In this case, the simulation of a shipping system includes models of operation, cargo loading, fuel loading, and docking for maintenance. In the simulation, various kinds of IoT technologies are defined by several input parameters. By changing the parameters, the simulator evaluates the impact of those technologies quantitatively. As a case study, 11 IoT technologies are evaluated and compared. The result reveals several insights that weight of the ship is the most impactful for the profit, controlling damage of the ship's hull by operation is the most important for safety, and improvement in efficiency at ports is the key to reducing delay time in operation. Moreover, this paper shows that the sensitivity analysis by changing the input parameters can support the decision making of how much investment will be effective in considering the technologies' levels.
\end{abstract}

Keywords Simulation $\cdot$ Decision support $\cdot$ Systems analysis $\cdot$ IoT $\cdot$ Maritime

\section{Introduction}

With the advance of information and communication technology, large amounts of marine equipment data can be transmitted to shipping companies during a voyage. By analyzing these data, more advanced ship operation and maintenance become possible.

Shinnosuke Wanaka

wanaka-s@m.mpat.go.jp

1 Graduate School of Frontier Science, The University of Tokyo, 5-1-5, Kashiwanoha, Kashiwa, Chiba 277-0882, Japan

2 Knowledge and Data System Department, National Maritime Research Institute, 6-38-1, Shinkawa, Mitaka, Tokyo 181-0004, Japan

3 Faculty of Engineering, Yokohama National University, 79-5, Tokiwadai, Hodogaya-ku, Yokohama 240-8501, Japan

4 LNG Group, NYK Line, 3-2 Marunouchi 2-chome, Chiyoda-ku, Tokyo 100-0005, Japan

5 System Design and Management, Massachusetts Institute of Technology, 77 Massachusetts Avenue, Cambridge, MA 02139, USA
Currently, the maritime industry seeks to take advantage of Internet of things (IoT) [1-4] technology. However, the adoption of IoT technologies in the maritime industry is still at an early stage [5]. However, effective use case scenarios of utilizing IoT technologies have been explored and studied [6-9], with each IoT technology of many diverse functions and candidate application sites. Given this diversity, decision making for the introduction of IoT requires many types of expertise. In addition, many sub-systems may be affected by introducing IoT. Therefore, the analysis of IoT insertion requires viewing complex ship operations as a whole system.

The objective of this paper is to support the introduction of IoT technologies in the maritime industry. The maritime industry is modeled as a system of systems, with criteria and functions treated in a simulation. The ship operation simulation includes models of ship operation, cargo and fuel loading, and docking for maintenance. In the simulation, various kinds of IoT technologies are defined by several input parameters, and by changing the parameters, the simulator evaluates the potential impacts of IoT technologies quantitatively. As a case study, 11 IoT technologies are evaluated and compared. The case study demonstrates the model and simulator in comparing those 11 technologies' contributions 
quantitatively, including systemic impacts achieved by the combination of the multiple technologies. Moreover, the level of IoT technologies is incorporated and, through sensitivity analysis, a decision support method is shown which trades effectiveness and investment.

\section{Systems model and analysis of the maritime industry}

For the sake of comparing effects from introducing IoT technology, it is necessary to determine the criteria and to develop a calculation method for the evaluation. In this section, the maritime industry is treated as a sociotechnical system, with stakeholder requirements and functions of the maritime industry. For the analysis, this paper applies several methods proposed by previous research [10-12] on sociotechnical systems and system of systems. This paper organizes those methods in two steps, analysis of stakeholder's expectations and logical decomposition of the system. Stakeholder analysis provides a holistic viewpoint of the overall system and enables one to evaluate and focus on more systemically relevant value flows. The maritime industry's system requirements emerging from the analysis are transformed into evaluation criteria, and a system function set from the logical decomposition becomes targeted functions that should be modeled in a simulation for evaluation.

\subsection{Analysis of stakeholder's expectations}

This research's problem space and system boundary are clarified through stakeholder analysis; a stakeholder value network (SVN) [13] is applied. Next, expectations of selected stakeholders are defined with the idea of functional/ performance requirement as shown in NASA's system engineering handbook [14].

Figure 1 shows an SVN of the maritime industry which shows value relationships between stakeholders within the maritime industry and its surroundings. In the figure, each rectangle represents a stakeholder. Arrows show the flow of value including goods or services between stakeholders. This figure is created by multiple interviews with people working in the maritime industry including shipping companies, shipbuilding companies, and the classification society.

While the maritime industry has various kinds of stakeholders as shown in the SVN, the interface between the public and shipping industry section is the interaction of the shipping companies and shippers. This paper focuses on this boundary-crossing interaction, a shipping service.

The primary function of the shipping service is to transport cargo from origin to destination. This paper adopts quality, cost, and delivery (QCD) $[15,16]$ as key performance requirements for the shipping company. Although other indexes such as QCDS (quality, cost, delivery, and service) [17] and QCDDM (quality, cost, delivery, development, and management) [18] could be considered, in this paper, we narrow down the evaluation to QCD which is the most basic and essential.

\subsection{Logical decomposition of a shipping service}

Next, in order to build a model for the evaluation of shipping system performance with IoT technologies, logical decomposition of the shipping service is performed using object

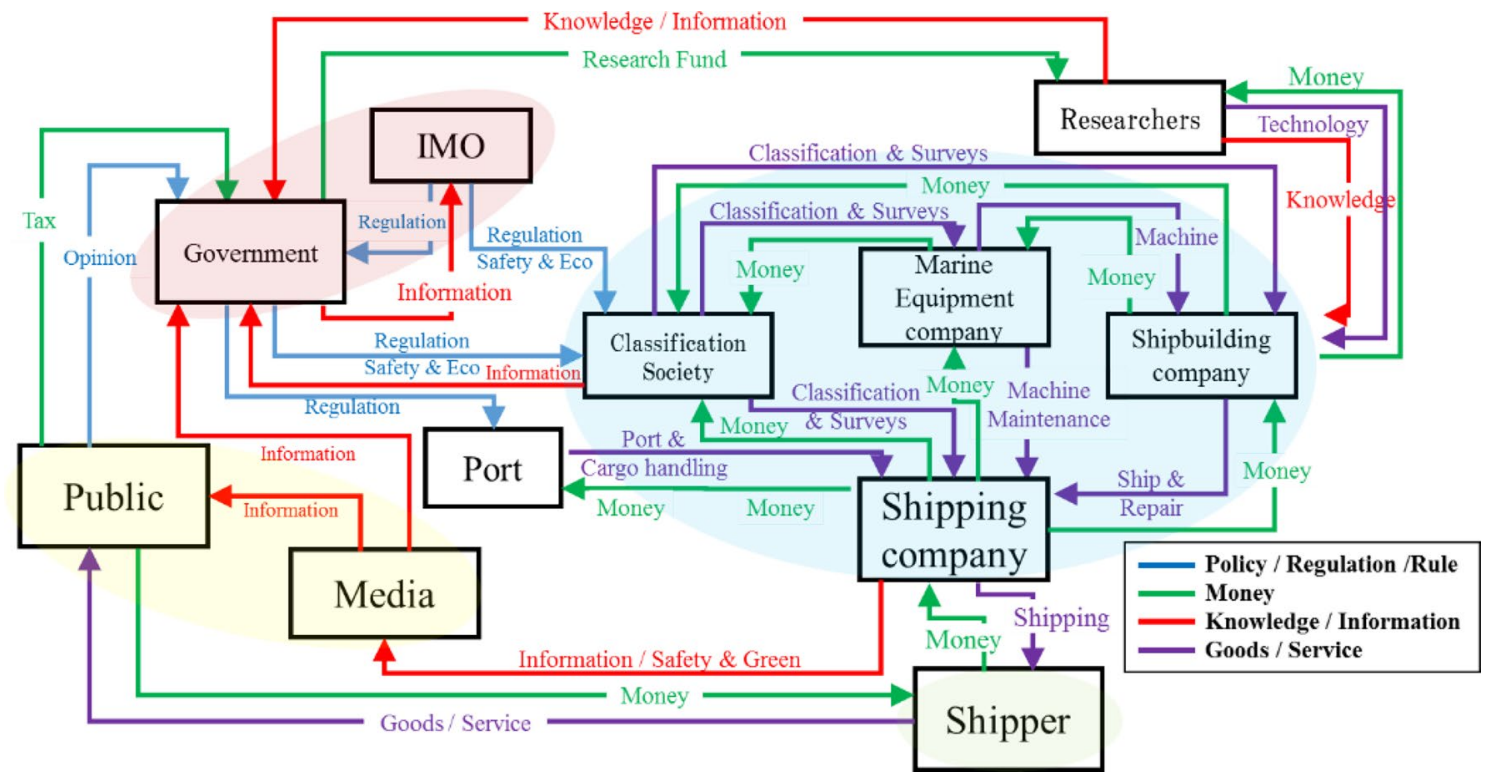

Fig. 1 SVN of maritime industry 


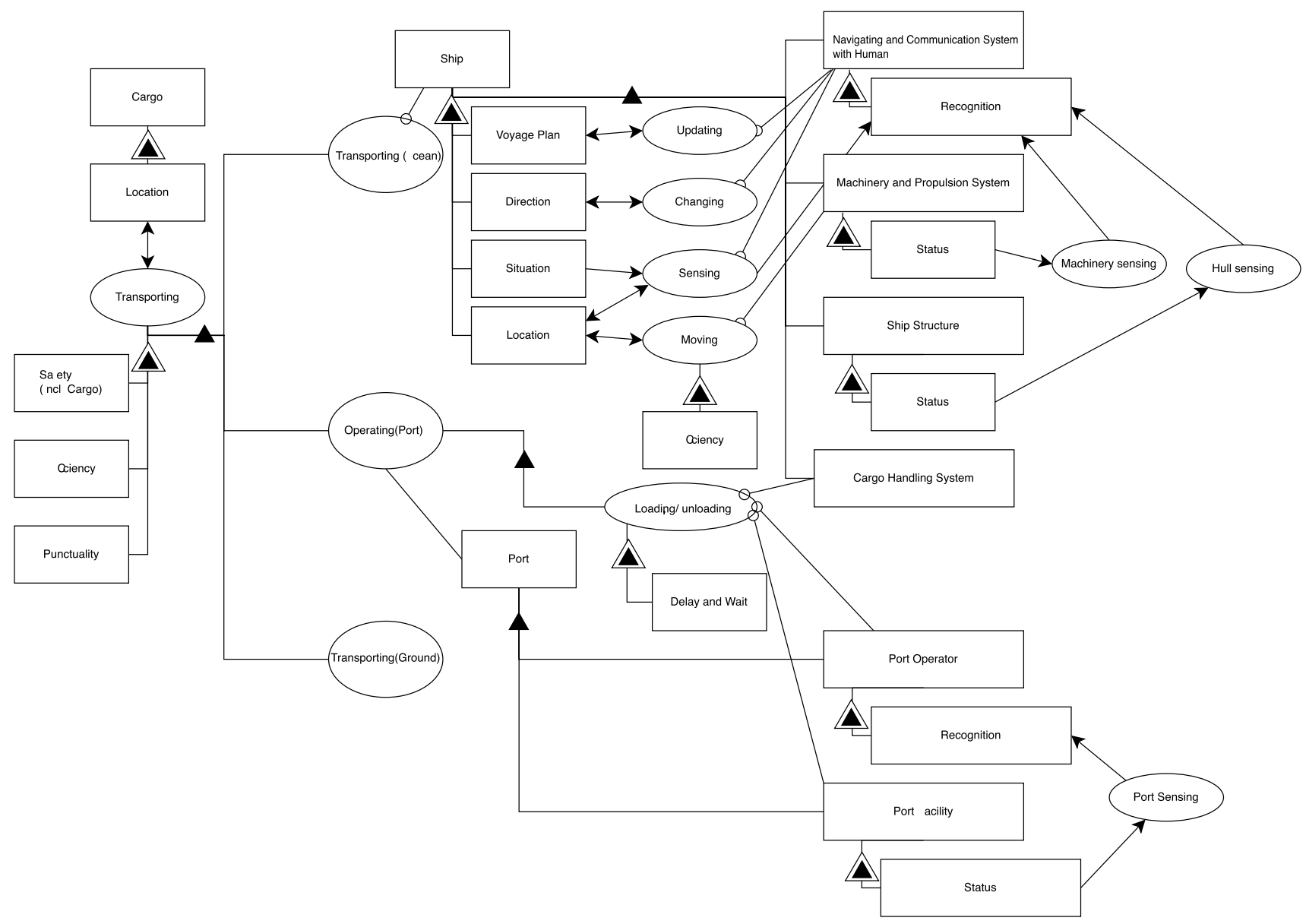

Fig. 2 System architecture of maritime industry modeled by OPM

process methodology (OPM) [19]. OPM is a conceptual modeling language and methodology for capturing knowledge and designing systems. The OPM model was developed based on our literature review and the interviews with experts from shipping companies, shipbuilding companies, and the classification society.

Figure 2 shows the results of the decomposition. In OPM, each ellipse shows a process as part of a function in ship operation. Each rectangle is an instrument that enables the function or an operand which is affected by the function.

Top-level functions of shipping service include transporting cargo and changing the location, and in this model, safety, efficiency, and punctuality are clarified as important performance indexes of the top-level function.

Transporting cargo is decomposed into internal functions: transporting on the sea, operating in ports, and transporting on the ground. The ship is an instrument of transporting on the sea and has properties including voyage plan, direction, situation, and location. The ship itself can be decomposed into internal instruments: a navigation and communication system, machinery and propulsion system, ship structure, and cargo handling system. The navigation and communication system includes humans who operate the system recognition as an attribute. The machinery and propulsion system and ship structure change and affect the ship's status. When sensing the status, the systems update the recognition of the navigation and communication system. As for operation in ports, the delay and wait time when handling cargos is modeled. Instruments of loading and unloading are cargo handling systems, port operators, and port facilities. Taken together, a system architecture model of the shipping service is shown in the diagram below. The introduction of IoT technologies may change the local performance of any function, and through systemic propagation, the change affects the global performance of the shipping service. This paper develops a simulator that can estimate functions of this system architecture and by adjusting parameters that define each instrument's performance, can represent the introduction of IoT technologies. 
IoT Technology Setting

ID 1

\begin{tabular}{|c|c|c|}
\hline Parameter & Default & IoT tech. 1 \\
\hline Engine failure rate & $\begin{array}{l}0.86 \\
\times 10^{-3}\end{array}$ & $\begin{array}{l}0.60 \\
\times 10^{-3}\end{array}$ \\
\hline Ship weight ratio & 1.00 & 0.95 \\
\hline$\cdots$ & $\cdots$ & $\cdots$ \\
\hline
\end{tabular}

ID 2

\begin{tabular}{|c|c|c|}
\hline Parameter & Default & IoT tech. 2 \\
\hline $\begin{array}{c}\text { Engine failure } \\
\text { rate }\end{array}$ & $\begin{array}{l}0.86 \\
\times 10^{-3}\end{array}$ & $\begin{array}{l}0.40 \\
\times 10^{-3}\end{array}$ \\
\hline Ship weight ratio & 1.00 & 0.98 \\
\hline$\cdots$ & $\cdots$ & $\cdots$ \\
\hline
\end{tabular}

ID 3

\begin{tabular}{|c|c|c|}
\hline Parameter & Default & IoT tech. 1 \\
\hline Engine failure rate & $\begin{array}{l}0.86 \\
\times 10^{-3}\end{array}$ & $\begin{array}{l}0.50 \\
\times 10^{-3}\end{array}$ \\
\hline Ship weight ratio & 1.00 & 0.90 \\
\hline$\cdots$ & $\cdots$ & $\cdots$ \\
\hline
\end{tabular}

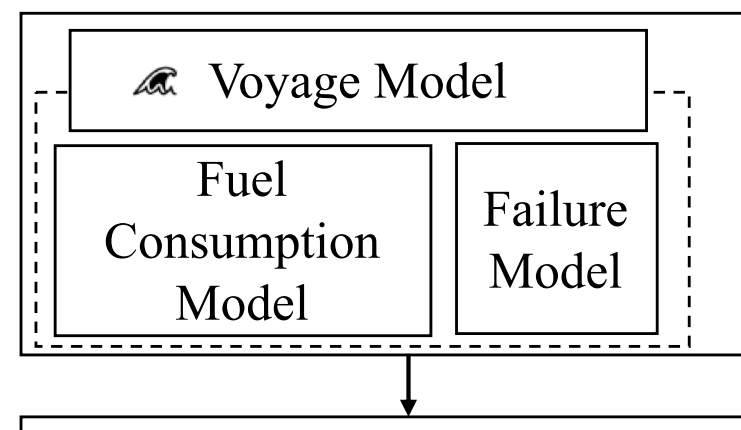

Simulation

$\oplus$

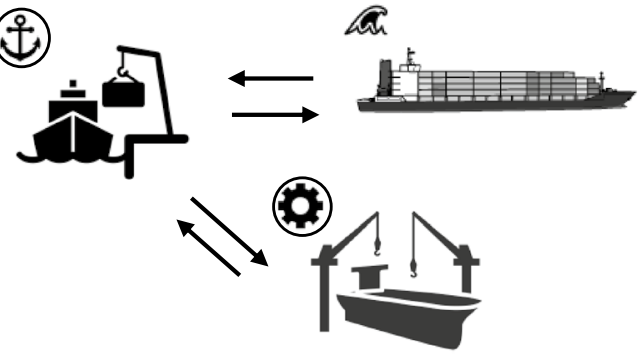

(i) Cargo Model

Dock Model

\section{Profit model}

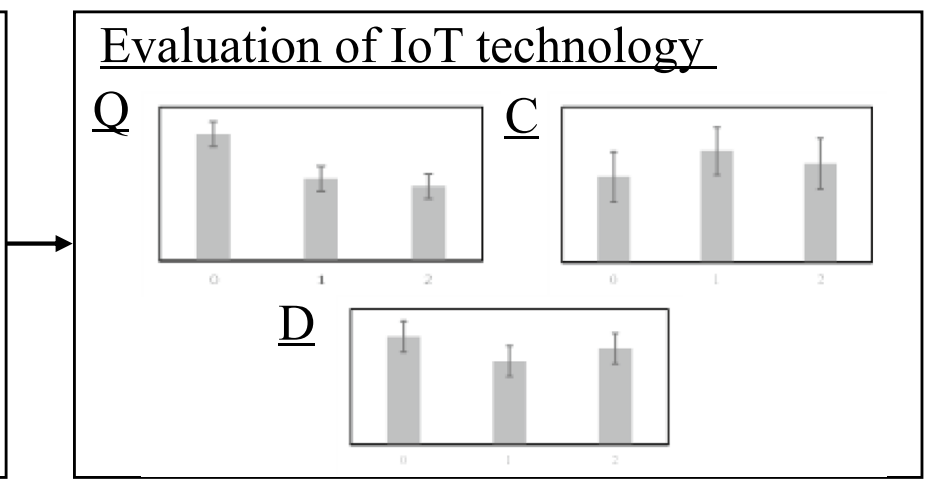

Fig. 3 Overview of the simulator

\section{Simulation for evaluation}

This section describes the simulator developed for a quantitative evaluation of the QCD of the shipping service. The expected use of this simulator is to evaluate the impact of IoT by adjusting process attributes. For example, changing delay and wait parameters of loading/unloading function affects QCD. This procedure to adjust attributes across the system as shown in the OPM diagram is repeated with one expectation: The attributed status of machinery and propulsion system is treated as a failure rate.

Figure 3 summarizes the parametric evaluation of IoT technology introduction. Following the requirements described in the previous section, the ship operation simulator generates the systemic effect on three indicators for one container ship: number of incidents and failures, operating profit, and delay time. Those indicators correspond to the shipping service's quality, cost, and delivery.

This paper assumes that the states of a ship in service are "operation," "cargo handling," and "docking." The number of incidents and failures, operating profit, flight delay, and cargo handling delay are calculated based on these models. In addition, this model considers the effects of weather conditions as external influences. The simulator does not consider the influence of market fluctuations, and it assumes fuel price and transportation fees as constant. In summary, the effect of introducing IoT is expressed by varying the parameters of the simulator and the effects are evaluated quantitatively. 


\subsection{Ship operation model}

A ship operation system includes models for calculation of fuel consumption, the number of incidents during operation, and the delay time.

The fuel consumption is modeled considering the following issues:

1. Ship performance including the effect of hull form, propeller, and engine,

2. Influence from deterioration or contamination,

3. Effect of weather condition,

4. Maneuvering effect,

5. Hull weight.

The ship performance and the influence of deterioration or contamination are modeled by utilizing basic ship theories and previous research [20]. Weather condition is considered by calculating fuel consumption increase rate under constant ship speed conditions with reference to ship speed reduction ratio per each Beaufort (BF) scale. The maneuvering effect is expressed by incorporating fuel consumption fluctuation by maneuvering $\left(\varepsilon_{\text {maneuvering }}\right)$ into the theoretical fuel consumption $\left(F O C_{\text {theory }}\right)$ as shown in Eq. 1. FOC $C_{\text {theory }}$ is a theoretical fuel consumption rate considering increase rate caused by the weather condition as Eq. 2. The ship speed reduction rate is calculated by a method proposed by [21]. Based on the reduction rate, the ship performance model is modified, and $\triangle S F O C$ is obtained. $\varepsilon_{\text {maneuvering }}$ is modeled as fluctuating value according to probability density function in the range of $0 \%-10 \%$ by Eq. 3. In this equation, $\alpha$ and $\beta$ are the parameters of maneuvering effects.

$F O C=F O C_{\text {theory }}\left(1+\varepsilon_{\text {maneuvering }}\right)$

$F O C_{\text {theory }}=S F O C \cdot(1+\triangle S F O C) \cdot \frac{B H P}{1000}$

$f\left(\varepsilon_{\text {maneuvering }}\right)=\frac{\left(\frac{\varepsilon_{\text {manewvering }}}{0.1}\right)^{\alpha}\left(1-\frac{\varepsilon_{\text {manewvering }}}{0.1}\right)^{\beta-1}}{\operatorname{Beta}(\alpha, \beta)}$

Hull weight effect is considered by setting the ship length $L[\mathrm{~m}]$, the flooded area $S\left[\mathrm{~m}^{2}\right]$, and the construction $\operatorname{cost} C_{\text {ship }}$ [\$] according to the following equations:

$$
\begin{aligned}
& L=L_{\text {theory }} \sqrt{W} \\
& S=S_{\text {theory }} W \\
& C_{\text {ship }}=C_{\text {ship,theory }} W
\end{aligned}
$$

BF scale of encountered weather condition is generated in accordance with the probability density function in the range of 1-7 in the same format as Eq. 3 .

The incident of voyage is modeled in consideration of ship hull failure, marine equipment failure, and marine incident. Regarding the incident/fault of hull and marine equipment, failure rate per voyage is modeled according to the general framework of reliability engineering theory. This failure rate is expressed as $R(t)$ in Eq. 7. $R(t)$ is calculated from Weibull distribution by using two parameters $(\sigma, \gamma)$ and damage accumulation value $t$ depending on the operation time. The damage accumulation value $t$ includes effects of fatigue, corrosion, and buckling.

$R(t)=1-\exp \left[-\left(\frac{t}{\sigma}\right)^{\gamma}\right]$

In order to consider weather condition and maneuvering effect, damage accumulation value $t$ is generated according to the probability density function dependent on $\mathrm{BF}$ and the steering damage influences parameter in the same format as Eq. 3. A certain probability of occurrence [case/voyage] for the maritime incident incidence rate is set in advance. The delay time associated with incidents and failures is set according to the beta distribution $(\alpha=2, \beta=2)$ with these average delay times as parameters.

\subsection{Cargo handling model}

Cargo handling is modeled taking into consideration the cargo handling equipment fault effect and the cargo handling work delay effect. A certain occurrence probability [case/port] for handling equipment failure and cargo handling delay is set.

The influence of cargo handling equipment failure is set according to the beta distribution $(\alpha=2, \beta=2)$ with the average delay time as parameter. The impact of cargo handling work delay is generated according to the average delay time and the probability density function represented by the parameters $\alpha$ and $\beta$ in the same format as Eq. 3. In this paper, cargo handling delay affects downtime and the cost of cargo handling.

\subsection{Docking model}

Docking model defines the rule, cost, and time of inspection taking account of the effect of classification inspection. Regarding the inspection rule, the following three rules are defined. At the time of docking, the degree of contamination and damage accumulation are updated to 0 .

- Docking should be done every 2.5 years.

- Docking should be done if the hull or propeller contamination rate exceeds $\mathrm{x} \%$. 
- Docking should be done if the hull fatigue rate exceeds $\mathrm{x} \%$.

\subsection{Profit model}

In the operation profit model, total operation cost is calculated based on operation revenue, fuel cost, cargo handling cost (cargo cost + port expenses), seafarer costs, construction costs, repair, and inspection fee.

The fuel cost depends on fuel consumption model. The cargo handling cost depends on cargo handling model. The repair and inspection fee depend on incident and failure model and docking model. Total operating revenue also changes depending on delay time. This paper does not take market fluctuation into consideration.

\subsection{Simulation procedure}

After inputting setting parameters, the developed evaluation simulator repeats a following procedure for each voyage until the end of operation period. Eventually, the simulator provides the number of incidents, profit, and delayed time during the overall operation. Each model includes a stochastic model so that Monte Carlo simulation approach is applied. By comparing the average and standard deviation of those indexes, it is possible to evaluate several options of IoT introduction.

1. Calculating cargo handing work effect: Simulator obtains the handling equipment failure and the presence or absence of cargo handling delay based on the cargo handling model. From this information, simulator calculates the delay time, downtime, and cost.

2. Acquiring weather condition: Simulator acquires the weather condition that targets container ship encounter from the ship operation model.

3. Calculating incident and failure effect: Simulator calculates delay time, downtime, and cost from the result of hull failure, marine equipment failure, and marine incident acquiring from the incident and failure model.

4. Calculating fuel cost: Simulator calculates fuel consumption and cost during voyage based on the ship operation model.

5. Recording income and expenditure: Simulator calculates delay time, number of incidents and failures, total time, and the profit from income and cost based on profit model.

6. Updating aging and fatigue effect: Simulator updates ship propulsion performance considering the impact of aging and contamination based on fuel consumption model. In addition, simulator updates damage degree of hull and marine equipment based on incident/failure model.

7. Judging whether target ship does dock or not: Simulator decides whether target ship does dock or not based on the docking model. If target ship is judged to do docking, simulator sets up to docking cost and docking time and at the same time resets the contamination rate and damage degree to 0 .

\section{Case studies}

\subsection{Target loT technologies}

In this case study, 11 IoT technologies were investigated which include not only already established ones but also still studied ones. The details of those technologies' explanations are as follows. In the explaining sections, ID is assigned to each technology to simplify the following explanation.

\subsubsection{Marine equipment monitoring}

By monitoring engine and other equipment, more appropriate and efficient maintenance will be expected [22]. Abnormal condition of each equipment can be detected by constantly acquiring IoT data of each equipment and analyzing these data at onshore side. Efficient equipment maintenance can be done by carrying out the maintenance only when abnormal condition is detected. In this case study, main engine monitoring (ID 1), voyage equipment monitoring (ID 2), and auxiliary power unit monitoring (ID 3) are the targets of the monitoring.

\subsubsection{Marine equipment remote maintenance}

By sharing information of equipment with marine equipment manufacturers in real time, downtime and cost for maintenance can be reduced. In addition, it is expected to avoid emergency stops on voyage and to shorten recovery time from emergency stop by realizing remote maintenance from onshore [23]. In this case study, main engine (ID 4) and auxiliary power unit (ID 5) are the targets of the remote maintenance.

\subsubsection{Hull load control system}

Technologies for controlling the load on the hull using IoT technology are not put to practical use at the present time. However, in other industry fields, there are cases such as decreasing the fatigue load by using control system. For instance, in the field of wind power generation, the pitch angle of the wing is controlled to reduce load fluctuation of the wind [24]. In maritime industry as well, avoidance of excessive load occurring during voyage and reduction in age deterioration of ship hull can be done by realizing the load control function which is done by controlling rudder, 
thrusters, and other additional devices based on IoT data (ID 6). It can be also assumed that hull weight reduction will be realized with the improvement in hull structure monitoring and load control technology (ID 7).

\subsubsection{Advanced weather routing}

Weather routing has already been in practical use. However, if the accuracy of measuring fuel consumption and weather condition is improved by using IoT technology, optimal fuel efficiency and safe voyage will be realized. By introducing IoT technology, weather routing is optimized for individual ship and becomes more advanced (ID 8).

\subsubsection{Cargo handling equipment monitoring and automation}

By constantly monitoring cargo handling equipment such as cargo handling cranes with IoT technology, maintenance and repair can be carried out in advance before failure of cargo handling equipment. Moreover, with the introduction of IoT technology, efficiency of operation of handling equipment and remote operation can be expected (ID 9).

\subsubsection{Streamlining port operation}

Logistics planning of all cargos and accuracy of port operation management have large impact of the efficiency of port operation. By constantly monitoring cargo movement and operation with IoT technology, it is expected that adequate port operation will be possible (ID 10).

\subsubsection{IoT utilization for ship design}

In the process of ship design, a great deal of labor is spent on making drawing and design plan by carrying out towing tank test and CFD. By introducing IoT technology, information exchange for designing ship will be more efficient (ID 11).

\subsection{Simulation scenario}

This case study assumes a container ship with 6600 TEU loaded which is operated as a shuttle between Los Angeles and Tokyo. The route distance is $8843[\mathrm{~km}]$ and the speed of the container ship is 19 knot that is $50 \%$ output of main engine. The lifecycle period of this ship is set as 20 years. Comparative evaluation for introducing each IoT technology is performed by the average and standard deviation of 1000 times Monte Carlo simulations result. We verified output distributions of the Monte Carlo simulation's result of baseline case.

Table 1 shows a list of changing parameters to represent each IoT technology. Level indicates performance level of each technology, and level 2 in Table 1 is used in case 1 as basic assumption of the case. Technology level in this paper is defined as a trade-off between the nominal performance of subsystems and cost. Usually, when people pay more costs, the system can demonstrate better performance. However, the change in the overall system's emerging performance is not linear and the balance between them is important for the decision making. That is the reason why technology level is introduced in this case.

Those parameters are carefully defined to be independent. When actually making a decision to introduce IoT
Table 1 Parameter setting of each IoT technology

\begin{tabular}{llllll}
\hline ID & Parameter to be changed & Base & Level 1 & Level 2 & Level 3 \\
\hline 1 & Main engine failure rate [case/h] & $0.86 \times 10^{-3}$ & $0.60 \times 10^{-3}$ & $0.40 \times 10^{-3}$ & $0.20 \times 10^{-3}$ \\
2 & Navigation equipment failure rate [case/h] & $1.14 \times 10^{-3}$ & $0.90 \times 10^{-3}$ & $0.50 \times 10^{-3}$ & $0.30 \times 10^{-3}$ \\
3 & Auxiliary machinery failure rate [case/h] & $3.21 \times 10^{-3}$ & $2.50 \times 10^{-3}$ & $1.50 \times 10^{-3}$ & $1.00 \times 10^{-3}$ \\
4 & Main engine recovery time [h/case] & 2.37 & 1.80 & 1.20 & 0.80 \\
& \# of crews [man] & 20 & 18 & 16 & 15 \\
5 & Auxiliary machinery recovery time [h/case] & 2.15 & 1.60 & 1.00 & 0.70 \\
& \# of crews [man] & 20 & 18 & 16 & 15 \\
6 & Damage distribution & Beta $(\mathrm{BF}, 4)$ & Beta $(\mathrm{BF}, 6)$ & Beta $(\mathrm{BF}, 8)$ & Beta $(\mathrm{BF}, 10)$ \\
7 & Weight ratio of ship & 1.00 & 0.95 & 0.90 & 0.85 \\
8 & Weather condition & Beta $(2,2)$ & Beta $(2,3)$ & Beta $(2,5)$ & Beta $(2,7)$ \\
9 & Cargo handling Cost [\$/port] & 50,000 & 48,000 & 45,000 & 40,000 \\
& Delay rate [case/port] & 0.10 & 0.08 & 0.06 & 0.04 \\
& Delay time [h] & Beta $(2,2)$ & Beta $(2,3)$ & Beta $(2,5)$ & Beta $(2,7)$ \\
10 & Port work cost [\$/port] & 50,000 & 45,000 & 40,000 & 37,000 \\
& Delay rate [case/port] & 0.10 & 0.08 & 0.06 & 0.04 \\
& Delay time [h] & Beta $(2,2)$ & Beta $(2,3)$ & Beta $(2,5)$ & Beta $(2,7)$ \\
11 & Construction cost [\$] & $200 \times 10^{6}$ & $199 \times 10^{6}$ & $195 \times 10^{6}$ & $190 \times 10^{6}$ \\
\hline
\end{tabular}



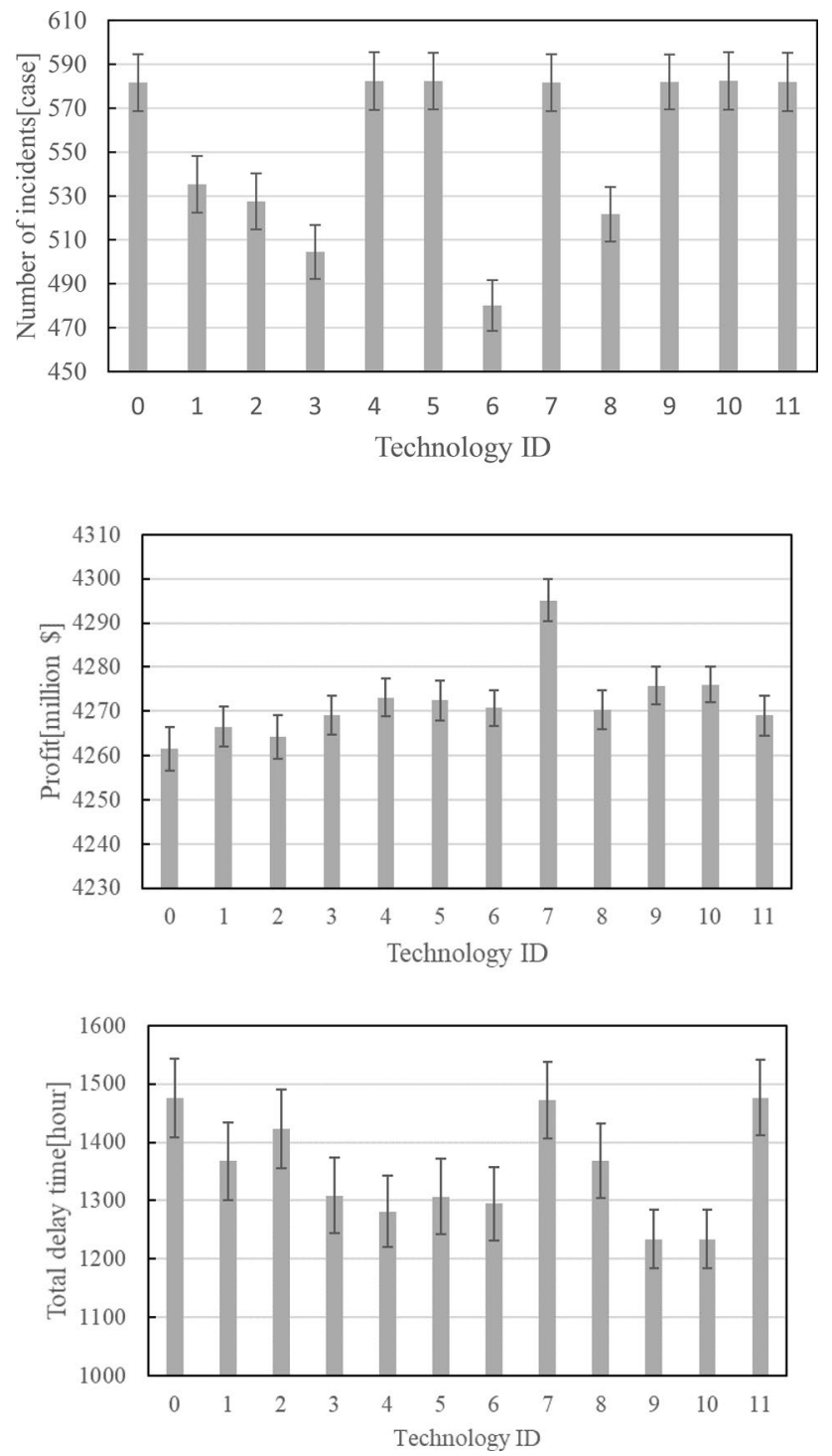

Fig. 4 Evaluation result of individual introduction of each IoT technology

technology, it is necessary to set the data that exist in the company that the decision maker belongs to and the technology level that the decision maker assumes as a parameter value. In this case study, the authors set the parameter values that are expected to be achievable within a few years, assuming improvements due to the introduction of IoT and AI into ship operations.

\subsection{Case: evaluation of each technology and the combination}

Figure 4 shows the simulation results of the number of incidents, operating profit, and total delay time by introducing each IoT technology. Horizontal axis means technology ID, and it is defined in Table 1. Each error bar indicates the standard deviations. ID 0 indicates the baseline performance in not introducing IoT technology. From Fig. 4, it is found that the effect of load control support (ID 6) is the best when its main purpose is to reduce the number of incidents. This is because this technology can reduce failures at multiple locations by reducing both hull fatigue and marine equipment level. From the viewpoint of improving operating profit, it can be said that reduction in material cost by load control system (ID 7) and reduction in construction cost by IoT in ship design are effective. When the main purpose is to reduce the delay time, the effect of remote cargo control or automatic cargo handling system (ID 9) and improving port efficiency (ID 10) is high. This is because that remote cargo control and automatic cargo handling system can reduce the delay time of cargo handling directly. Also, by making the port operation more efficient, the total delay time can be reduced and improve efficiency of total ship operation. As described above, by representing the impact of various IoT technologies as changing parameters, the developed simulation can discuss the effectiveness of introducing IoT technology by comparing each technology from the viewpoint of shippers' QCD.

Moreover, the simulation can evaluate the combination of those technologies. Figure 5 shows the result of evaluation of profit by two technologies combination. Its horizontal and depth direction indicates IoT technologies ID, and they constitute a matrix. The vertical direction means non-dimensional value of profit from the operation which shows the ratio of the profit divided by the baseline performance. Figure 5 shows that there are interactions between some of the IoT technologies. For example, ID 7 reduces hull weight by controlling loads, and ID 11 reduces construction costs by making production more efficient. There are synergies in these, and the effects on profit are more than simple summation. As a result, the combination of these will have the highest impact on profit although ID 11 alone is not among the highest.

\subsection{Sensitivity analysis}

In this section, sensitivity of parameters representing IoT technology and the effect of improvement in each IoT technology are analyzed. Each stage of IoT technologies maturities is defined in Table 1. By observing the impacts of technology levels $1-3$, sensitivity analysis is conducted. Figure 6 shows the evaluation results in consideration of each IoT 
Fig. 5 Evaluation result of profit by combinational introduction of two IoT technologies

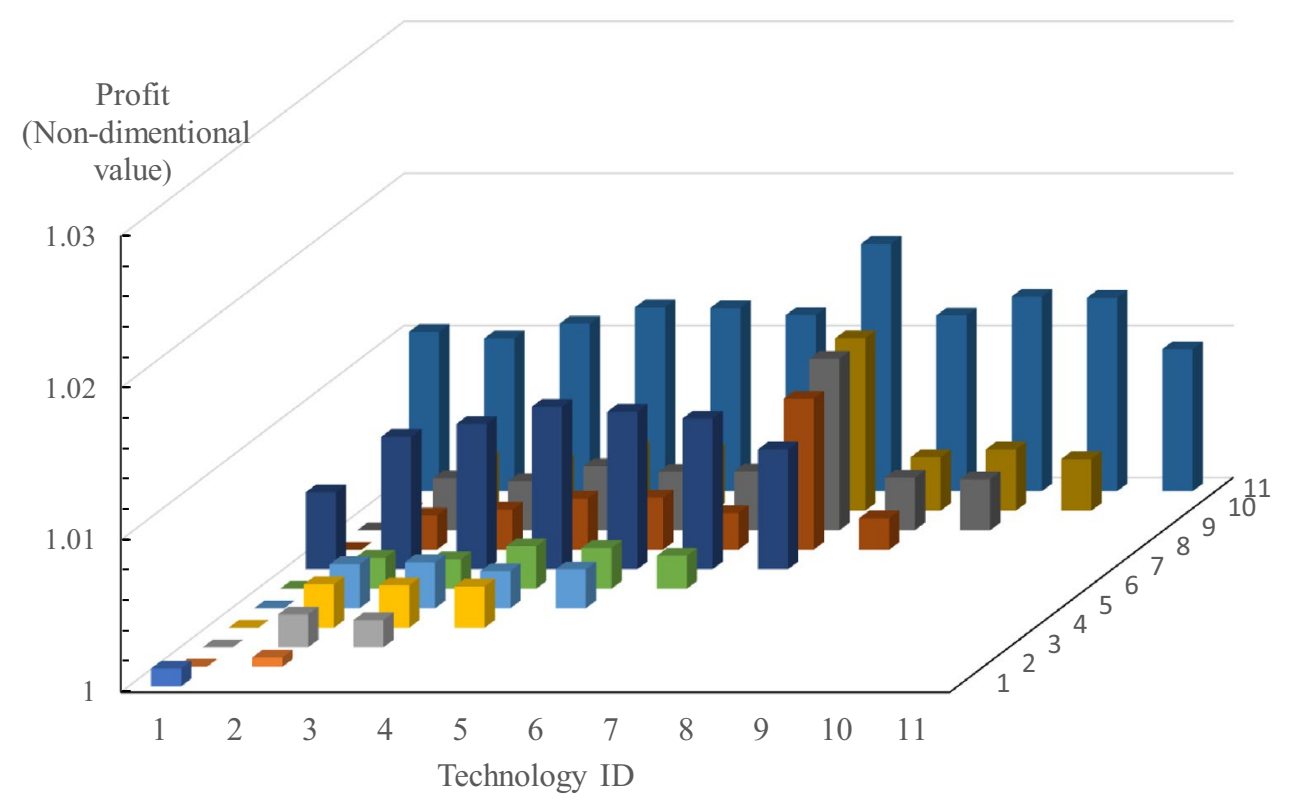

technology level. Level 1 is low, level 2 is medium, and level 3 is high in the technology level.

From the viewpoint of the number of incidents, the technology level of marine equipment monitoring (ID 1-3), load control (ID 6), and weather routing (ID 8) has high sensitivity. In addition, these technologies have similar characteristics with respect to the total delay time. This is because the number of incidents is decreased by the introduction of IoT monitoring system and that as a result, downtime by incidents is reduced. From the viewpoint of operating profit, the sensitivity of load control support technology (ID 7) is the highest. It is rational that the most cost of ship production derives from the materials, and by reducing material cost by load control system, it can reduce ship's capital cost. From the viewpoint of delay time, the technologies related to decreasing the number of incidents have high sensitivity. In addition, it shows that auxiliary power unit maintenance improvement (ID 5) and cargo handling-related technology (ID 9, ID 10) have high sensitivity as well.

Through considering technology level as this case, it is possible to discuss which level of IoT technologies is needed and how much cost can be invested to the technology for realization of the level. When the contribution of the technology becomes high with small investment, the technology is a good candidate of the investment. It is important to carefully examine what level of the technology level should be a target to pay off the investment in order to make a reasonable decision.

\section{Discussion}

This paper assumes parameters including current ships' performance and future technology improvement. However, actual performance parameters highly depend on operation context, such as route, ship type, and operating company, and include other uncertainties as well. For actual decision making by a company, the company leveraging a similar method would refine the inputs for accuracy and appropriate assumptions suitable for their situation. Over time, the company can model various future improvement scenarios and obtain evaluation result from the field quantitatively.

This research does not consider difficulties and development cost of introducing the technologies. However, the model and simulator can provide information on how much the technologies contribute to their company quantitatively. With the contribution regarded as a break-even point, and if costs are higher than the contribution, the technology should not be introduced. Cost and difficulty expectation are outside of this paper's scope, yet once obtained, the decision maker can calculate the cost-effectiveness based on the simulation's result. These model-based results may serve as a basis for stakeholder dialogue on which technology is the best to introduce.

A limitation of this research is the consideration of only one ship's operation and evaluated the impacts of IoT. However, several IoT technologies might show their increased value when it is introduced into a fleet. By interacting among ships in the fleet, the impacts might increase nonlinearly. This paper does not take the nonlinearly increased impact into account. To consider the kind of impact, this research could be extended as a model of fleet operation, interaction between the system effects by the IoT technologies. 

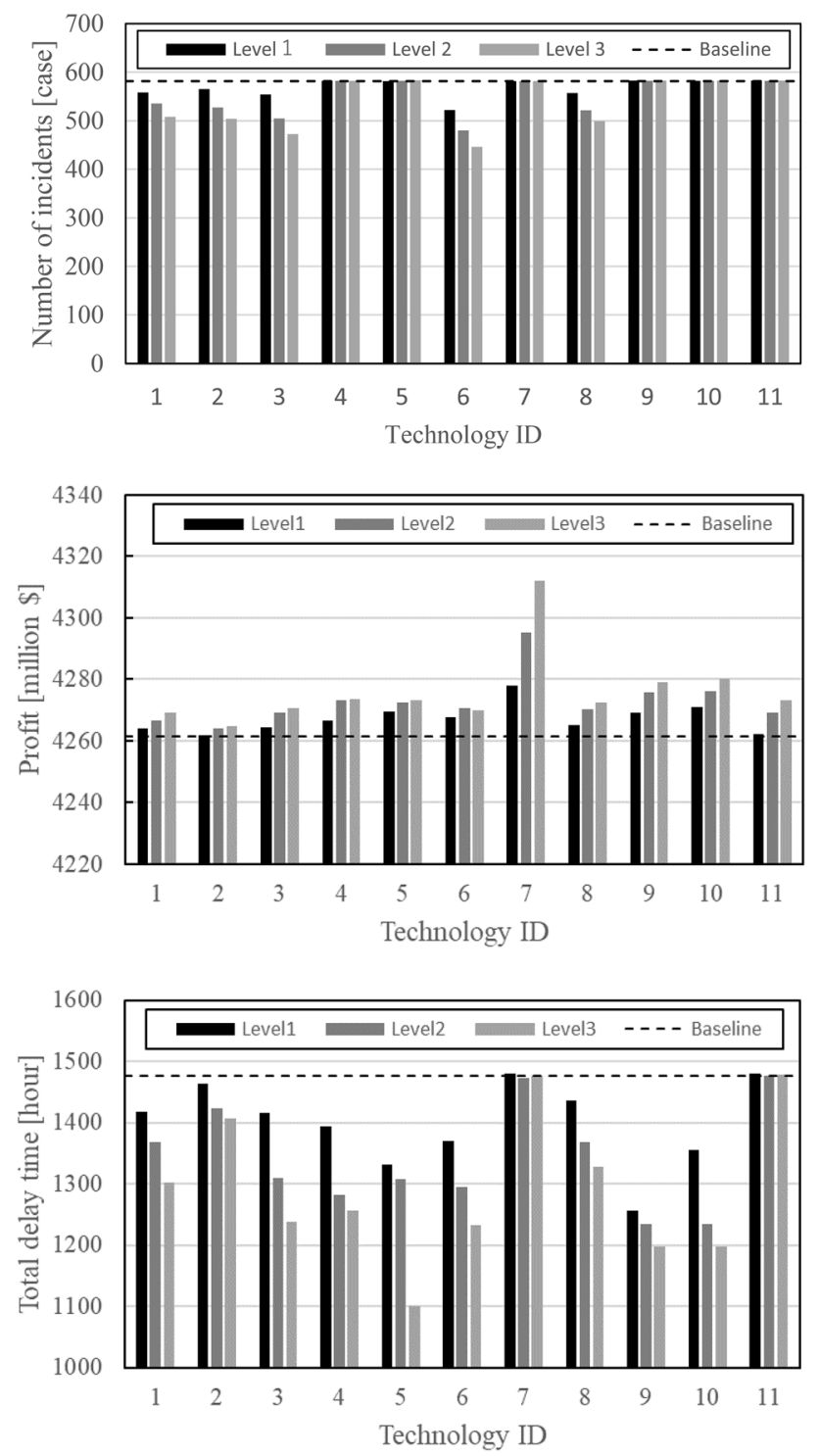

Fig. 6 Results of sensitivity analysis by changing input parameters of each IoT technology

Accuracy of the parameters evaluated in the case is another limitation. In the case study, the authors set the parameters of IoT technologies. However, when actually making a decision to introduce IoT technology, it is important to set the data that exist in the company that the decision maker belongs to and the technology level that the decision maker assumes as a parameter value.

\section{Conclusion}

The objective of this paper is to support decision making for IoT introduction in the maritime industry. A ship operation model and simulation were developed to evaluate the impacts of IoT. A stakeholder value network informed requirements, and an object process (OPM) systems model represented the maritime industry, evaluation criteria, and target functions. Based on these models, a simulation handles ship operation, cargo and fuel loading, and docking for maintenance, and various kinds of IoT technologies defined parametrically. With a specific ship defined, the simulation calculates lifecycle performance.

As a case study, 11 IoT technologies were evaluated and compared for a specific container ship with the simulation. The case study demonstrated the simulator could evaluate and compare those technologies' contribution quantitatively. The result reveals several insights that weight of the ship is the most impactful for the profit, controlling damage of ship's hull by operation is the most important for safety, and improvement in efficiency at ports is the key to reducing delay time in operation. Also, the 3D bar graph shows the systemic impacts which were achieved by the combination of the multiple technologies. Moreover, it showed that the sensitivity analysis by changing the input parameters could support the decision making of how much investment will be effective in considering the technologies' levels.

The authors suggest further research that considers the impact of market uncertainty such as fuel price fluctuation and increasing transportation demand. Those are drivers to make the shipping system more complicated, and IoT technology might have the potential to manage those uncertainties. To reveal those effects is important. And also, an impact on environmental performance can be an interesting topic because a reduction in GHG emissions has received a lot of attention in these days. Additional model development is necessary for those future researches.

Open Access This article is licensed under a Creative Commons Attribution 4.0 International License, which permits use, sharing, adaptation, distribution and reproduction in any medium or format, as long as you give appropriate credit to the original author(s) and the source, provide a link to the Creative Commons licence, and indicate if changes were made. The images or other third party material in this article are included in the article's Creative Commons licence, unless indicated otherwise in a credit line to the material. If material is not included in the article's Creative Commons licence and your intended use is not permitted by statutory regulation or exceeds the permitted use, you will need to obtain permission directly from the copyright holder. To view a copy of this licence, visit http://creativecommons.org/licenses/by/4.0/.

\section{References}

1. Atzori L, Iera A, Morabito G (2010) The internet of things: a survey. Comput Netw 54(15):2787-2805

2. Gubbi, J.,Buyya, R., Marusic, S. andPalaniswami, M.(2013) Internet of things (IoT): A vision, architectural elements, and future directions. Future Generation Comput Syst 29(7):1645-60 
3. Zanella A, Bui N, Castellani A, Vangelista L, Zorzi M (2014) Internet of things for smart cities. IEEE Internet of Things $\mathrm{J}$ $1(1): 22-32$

4. Fleisch E (2010) What is the internet of things? An economic perspective. Econ Manag Financial Markets 5(2):125-157

5. Agrifoglio R, Cannavale C, Laurenza E, Metallo C (2017) How emerging digital technologies affect operations management through co-creation. Empirical evidence from the maritime industry. Prod Plann Control 28(16):1298-1306

6. Choi HR, Moon YS, Kim JJ, Lee JK, Lee KB, Shin JJ (2018) Development of an IoT-based container tracking system for China's Belt and Road (B\&R) initiative. Maritime Policy Manag 45(3):388-402

7. Liu G, Perez R, Muñoz JA, Regueira F (2016) Internet of ships: the future ahead. World J Eng Technol 4(03):220

8. Chiappetta A (2017) Hybrid ports: the role of IoT and CyberSecurity in the next decade. J Sustain Dev Trans Logistics 2(2):47-56

9. Park N, Bang HC (2016) Mobile middleware platform for secure vessel traffic system in IoT service environment. Security Commun Netw 9(6):500-512

10. Crawley, E., Cameron, B., and Selva, D. (2016) System architecture-strategy and product development for complex system, PEARSON.

11. Frank M (2000) Engineering systems thinking and systems thinking. Syst Eng 3(3):163-168

12. L. de Weck,O., Roos,D., and L. Magee,C. (2011) Engineering systems, THE MIT PRESS.

13. Cameron B, Crawley E, Loureiro G, Rebentisch E (2008) Value flow mapping: using networks to inform stakeholder analysis. Acta Astronaut 62:324-333

14. Hirshorn, S. R., Voss, L. D., and Bromley, L. K. (2017). Nasa systems engineering handbook.
15. Amasaka K (2007) New Japan production model, an advanced production management principle-key to strategic implementation of new JIT. Int Business Econ Res J 6(7):107-114

16. Yamada S, Yamashita T, Fukuta A (2010) Product quality prediction based on software process data with development-period estimation. Int J Syst Assurance Eng Manag 1(1):72-76

17. Handfield R, Walton SV, Sroufe R, Melnyk SA (2002) Applying environmental criteria to supplier assessment: a study in the application of the analytical hierarchy process. Eur J Oper Res 141(1):70-87

18. Burnes B, New S (1996) Understanding supply chain improvement. Euro J Purchasing Supply Manag 2(1):21-30

19. Dori, D. (2002) Object-Process methodology: A holistic systems paradigm, Springer.

20. Hiekata K, Mitsuyuki T, Moser B, Yamato H, Saito T, Wanaka S (2016) A study on ship life cycle value maximization with flexible design considering real option. J Jpn Soc Naval Architects Ocean Eng (in Japanese) 23:231-237

21. Tsujimoto M, Kuroda M, Shibata K, Sogihara N, Takagi K (2009) On a calculation of decrease of ship speed in actual seas. J Jp Soc Naval Architects Ocean Eng 9:79-85

22. DNV GL (2014) Beyond condition monitoring in the maritime industry, DNV GL Strategic Research \& Innovation Position Paper 6-2014.

23. DNV GL (2015) Ship connectivity, DNV GL Strategic Research \& Innovation Position Paper 04-2015.

24. Yu, H., Choi, J., Han, S., Tai, S., and Ha, M. (2008) Full scale measurement of a large container carrier on the far east Europe route, Singapore Maritime Technology Conference.

Publisher's Note Springer Nature remains neutral with regard to jurisdictional claims in published maps and institutional affiliations. 